\section{Dos obras en balnearios}

Miguel Eyquem Profesor, Escuela de Arquitectura, Universidad Católica de Valparaíso

En el recorrido de dos obras del borde costero, estas son analizadas desde la percepción y los sentidos. El recorrido del autor por la obra, como un relato pausado y reflexivo, trae a discusión dos maneras de ocupar un terreno al borde, junto al mar.

CASAS EN LA COSTA / Obras que pertenecen a un programa muy establecido, indiscutido por su situación privilegiada: estar en el borde, en el límite mismo del territorio, una situación exigente. Vivimos en un país de montañas como Grecia, donde todos los santuarios y grandes ciudades están referidos de alguna manera al mar. Vivimos en valles interiores, cercados con horizontes próximos, altos, en calles amuralladas o cercadas por árboles que se tragan el espacio.

La llegada a la costa al encuentro de ese horizonte lejano sin medida, de profundidad infinita, es una línea en tensión, inalterable, permanente, cuando se muestra. Vacío sin habitar, pero una superficie con vida propia, siempre cambiante, variando de opaco a brillante; de color saturado al reflejar todos los dibujos y colores del cielo o jugar con el sol todas las posibilidades de la luz. Una extensión abierta que nos fascina con su temperamento enigmático.

Una casa que se instala en este borde destacado, es un gran desafío, para enfrentarlo con humildad y sobriedad.

Casa El Morro, Zapallar. Teodoro Fernández / Un largo frente $(+-30 \mathrm{~m}$ ) enfrentando el horizonte, paralelo. Los extremos poseen sus propias orientaciones: hacia el sur, terraza frente a los árboles, el fresco oscuro de los pinos del lugar despeinados por el viento. El otro extremo del largo rectángulo sufre una inflexión buscando su propio horizonte. Sin alterar el volumen simple rectangular del techo, el interior en el primero y segundo piso resultan girados sus frentes hacia ese horizonte norte. Es uno de los lugares más logrados. Una terraza proporcionada a tan vasto espacio (al interior y al exterior). En el giro resultante se repliega el ventanal del extremo induciendo una sombra generosa bajo techo. La terraza en segundo nivel con su piscina acoge al terreno posterior incorporando esa umbra bajo algunos pinos en una pendiente caminable. En esa articulación comparece la integridad del lugar: el vasto mar despejado y el trozo de tierra costera. Un lugar acogedor habilitado.

Volviendo a la costa, encuentro con la casa El Morro, una colina. La casa se instala de tal manera que aparece coronando una altura entre unos negros pinos de la costa. Una naturaleza curva rectificada por unos planos rectos entre líneas rectas remarcadas: largas horizontales referidas directamente al horizonte marino. Se presenta de un golpe de vista: un block unitario sobre una base elevada. Generalmente es un problema insuperable acceder por el frente a una casa que exige liberar ese frente. Aquí es posible, en la ley de la pendiente tratada por niveles bien definidos, dentro de la geometría curva de la puntilla.

Aproximándose desde una avenida a $18 \mathrm{~m}$ más abajo, el nivel habitable conserva su intimidad: una gran plataforma que no muestra ningún muro de contención pues el primer nivel de hormigón contiene un
These two works on the coast are analyzed from the perspective of perception and the senses. The author reviews the work through a slow and reflexive narrative and debates two ways to occupy a plot of land on the edge of the sea.

pequeño rebaje. La configuración del lugar, sólo enmarcada en sus negros pinos, es independiente de cualquier vecino. Es importante la velocidad del viento acelerado en esa puntilla avanzada sobre el mar. Un plano de celosías de madera ocre luminoso entre fuertes rectas negras, unos perfiles metálicos suficientemente largos y sin arrugas para peinar el viento. En este sentido, aerodinámico aunque esté enmarcado en perfiles duros, a escuadra. Una magnitud que se inserta en las exigencias del lugar natural (Le Corbusier habría dicho une dimension conforme), acorde a la totalidad del fenómeno, no vencerlo, sólo trabajar con sus leyes, como estos pinos despeinados por el viento; es su forma de jugar con él. Magnitudes aquí justas.

Aproximándose hacia la puerta, en un nivel bajo el primer piso, el cual pertenece a los dormitorios, se avanza junto a la casa y sus jardines, bajo el volado del piso superior que aparece muy liviano, entablado de madera por abajo. El frente del primer piso es una franja de vidrio larga, una sucesión de ventanas continuas que cierran una caja de hormigón saliente al interior, a una altura de asiento, como un bow window, mostrando el carácter de salitas que ofrecen los dormitorios. Subiendo la escalera exterior se llega frente a un cubo de madera que avanza a partir de dos vidrios del hall de acceso. Este cubo, un pequeño porche que sale a recibir, con su tacto cálido de madera, es un aviso de como será esta casa en su interior acogedor.

Accediendo al segundo nivel por una escalera recta, se llega en medio de un living amplio, generoso, donde cae una iluminación cenital al costado originada por un periscopio sobre el techo, equilibrando el ventanal corrido del poniente. Devolviéndose hacia la izquierda, aparece el comedor frente a una ventana vertical al oriente, coronada por un periscopio noreste, una luz especial. Se puede hablar mucho de la intervención de estas iluminaciones a lo largo del día para templar el interior, también de la verdadera extensión del living-puente con sus terrazas y sus sombras, terraza norte inflexionada por la atracción del horizonte, donde se reúnen todos los espacios en juego, en fin, un centro de vida. Los detalles que proporcionan calidad de vida: los perfiles industriales del borde del muy liviano techo, por su estructura metálica. La baranda de borde de metales delgados con un pasamano revestido de madera: el entablado del living-puente, sus niveles; el detalle del cubo de madera para el acceso en primer nivel, entre vidrios... etc.

Casa en Punta Pite, Papudo. Smiljan Radic / Borde de mar, camino de cornisa frente al horizonte. En el camino sólo una puerta metálica cierra un acceso tangente al mismo. Tras el portón eléctrico, se inicia una rampa recta mostrando la configuración de este urbanismo para ocupar un terreno abrupto y mineral. Sólo las rocas y el mar. 


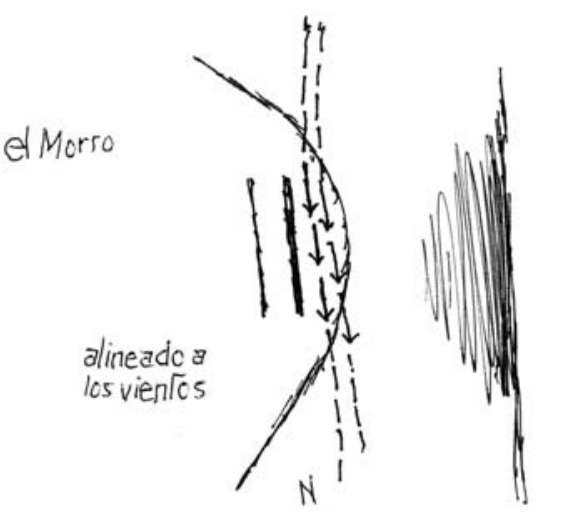

El terreno urbanizado por cinco tramos rectos en zigzag que lo abarcan. Cuatro rampas de suave pendiente, largas, para la contemplación. La primera rampa recta, la de autos, conduce a una terraza de estacionamientos limitada a un sector. La llegada al primer volumen es más distante, se cuida la intimidad. Los obstáculos son unos menhires de piedra dispuestos en un orden que muestra, en una primera mirada, la composición del espacio, un primer indicio de la medición de estos importantes espacios. Al interior, en un nivel inferior, se descubrirá que esta primera terraza es el techo de un ala de dormitorios. El lugar es transitable sólo por estas cintas de hormigón que se extienden entre articulaciones que conforman los giros, un hecho arquitectónico que mide la distancia, el alejamiento. Estos encuentros se componen con la sombra de los escalones que cambian niveles, muros de contención, más bien de ordenación, que acompañan el recorrido.

Al avanzar por estas circulaciones de hormigón sobre unos pavimentos bien dibujados, se van descubriendo los diferentes cuerpos que componen el proyecto. Dos conviven yuxtapuestos, un tercero, está distante, a otro nivel, independiente. Esta urbanización en su conjunto como una sola pieza es leve, apenas toca el terreno. No hay muros de contención a la vista. Los cuerpos cristalográficos se posan sobre las rocas mostrando su nueva generación de piedra reconstituida con sus aristas agudas, junto a ellas, redondeadas por la acción del tiempo. A nivel de la terraza principal se accede a un interior, desde donde se alinean a una cierta distancia del frente norte, algunos árboles que darán sombra.

El manejo de la abstracción: aproximación a un cuerpo a través de una terraza, una verdadera plataforma extensa enfrentando un volumen horizontal largo que ocupa ese horizonte y se prolonga en el mar. Una aproximación larga enfrentando esos ventanales enmarcados en madera; se toma un tiempo, una preparación. Un frente vidriado de líneas perfectas. Cantos de terminación industrial (aquí no hay hojalatería), grandes marcos de maderas nobles barnizadas para desplazar grandes vidrios, una puerta pivotada de $1.50 \mathrm{~m}$ que gira, una escala generosa de gran calidad de diseño, como los espacios, proporcionan un volumen impecable, las verdaderas líneas rectas de la geometría cartesiana.

Frente al mar, al interior, un plano transparente. Una sola hoja de vidrio da una pared invisible. Los marcos desaparecen, el vidrio tratado como otro material de construcción: podría resistir el techo (problema de espesores). Eso es aquí un acierto: que desaparezcan los enmarcamientos, como en la pintura abstracta de nuestro tiempo, y en la oriental. El cuadro es un recorte del espacio exterior. En el dormitorio se está más próximo a estos hechos. Una aproximación hacia este recorte del inmenso espacio marino para agrandar esta maravilla de estar volcados hacia ese exterior único. Súbitamente, sin quererlo, el cuerpo se detiene,

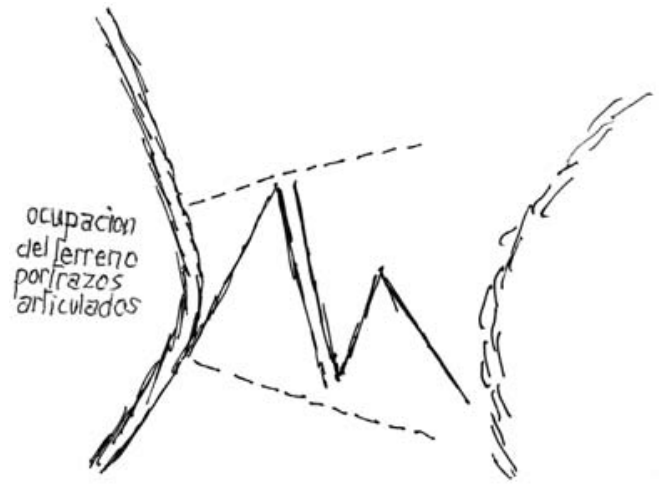

un instinto automático lo distancia del borde del piso de hermosa madera, que termina en el vacío. A esta reacción la llamamos vértigo, el que aparece, aunque la altura sea poca. ¿Por qué? Hay que analizar qué cosa nos detiene. Nos podemos apoyar en el horizonte, ese plano azul extenso y apacible, pero avanzamos y miramos el suelo porque es un borde. Aquí no hay borde, porque no hay marco. La magnífica abstracción del vidrio lo ha borrado; estamos ante la pura transparencia: esto está plenamente logrado. Entonces, proyectados al vacío, con las rocas abajo, no somos capaces -naturalmente- de volcarnos hacia él. Falta algo, los pies necesitan topar, un pequeño perfil que limite su deslizamiento. Al resto del cuerpo no le basta el apoyo del ojo en el horizonte, pues este lo ha situado en una profundidad infinita. El cuerpo quiere ayuda a nivel de su centro de gravedad, una baranda, aunque sólo fuera para apoyar el ojo: una línea pintada en el vidrio. Los franceses la llaman garde-corps: es el significado exacto. Es claro que podría ser este cuarto muro de materia transparente respetando estas dimensiones de seguridad que nuestro cuerpo lleva inscritas en su programa. Este encuentro nos hace meditar sobre la arquitectura: sobre la habitabilidad. Pero la pureza nos lleva más lejos: esta magnífica placa invisible va a retener cierta radiación solar que la calienta convirtiéndose, a su vez, en radiador. Hay entonces problemas climáticos. Nuestro tiempo ha visto las venecianas y todas sus variantes, pero ellas detienen la radiación calentándose al interior. Así, nos quedamos con el problema porque hay que salir al exterior: un quebrasol. Cualquier forma de quebrasol será un artefacto agregado a la belleza cristalina del cubo cortado con galleta. Entonces estamos obligados a aceptar que nos falta algo: nos falta más diseño. Es decir, para acercarnos a esa perfección que admiramos en el Partenón, hoy día estamos obligados a llevar nuestros diseños al extremo. Claro que podríamos parar el sol por medio de un dispositivo lo suficientemente alejado para que no forme parte del volumen cristalino, que no interfiera su composición. Esos dispositivos se convertirían en otros hechos espaciales que generarían distracción. Se perdería la simplicidad alcanzada por el conjunto.

ComentARIo / Esta forma de aproximarse a las obras a través de visitas, podríamos llamarla visitas comparadas, se revela como una buena ocasión de conversar sobre arquitectura, Una ventana abierta sobre tópicos candentes en el presente que vivimos y se presta a posteriores trabajos sobre materias del mayor interés que las obras provocan. Aquí sólo han quedado enunciadas algunas y otras en el tintero, como por ejemplo: el problema de la degradación de la materia, el mantenimiento.

Estas dos obras descritas aquí ofrecen el más grande interés pues son esmeradamente bien realizadas, con gran amor al oficio, se prestan a una real discusión arquitectónica. ARQ 